\title{
Improvement of alkalophilicity of an alkaline xylanase Xyn11A-LC from Bacillus sp. SN5 by random mutation and Glu135 saturation mutagenesis
}

Wenqin Bai ${ }^{1,2^{*}}$, Yufan Cao ${ }^{1,2}$, Jun Liu ${ }^{1,2}$, Qinhong Wang ${ }^{1}$ and Zhenhu Jia ${ }^{2^{*}}$

\begin{abstract}
Background: Family 11 alkaline xylanases have great potential economic applications in the pulp and paper industry. In this study, we would improve the alkalophilicity of family 11 alkaline xylanase Xyn11A-LC from Bacillus sp. SN5, for the better application in this field.

Results: A random mutation library of Xyn11A-LC with about 10,000 clones was constructed by error-prone PCR. One mutant, M52-C10 (V116A and E135V), with improved alkalophilicity was obtained from the library. Site-directed mutation showed that the mutation E135V was responsible for the alkalophilicity of the mutant. The variant E135V shifted the optimum pH of the wild-type enzyme from 7.5 to 8.0. Compared to the relative activities of the wild type enzyme, those of the mutant E135V increased by 17.5, 18.9, 14.3 and $9.5 \%$ at pH 8.5, 9.0, 9.5 and 10.0, respectively. Furthermore, Glu135 saturation mutagenesis showed that the only mutant to have better alkalophilicity than E135V was E135R. The optimal pH of the mutant E135R was 8.5, $1.0 \mathrm{pH}$ units higher than that of the wild-type. In addition, compared to the wild-type enzyme, the mutations E135V and E135R increased the catalytic efficiency $\left(k_{\text {cat }} / K_{m}\right)$ by 57 and $37 \%$, respectively. Structural analysis showed that the residue at position 135 , located in the eight-residue loop on the protein surface, might improve the alkalophilicity and catalytic activity by the elimination of the negative charge and the formation of salt-bridge.

Conclusions: Mutants E135V and E135R with improved alkalophilicity were obtained by directed evolution and site saturation mutagenesis. The residue at position 135 in the eight-residue loop on the protein surface was found to play an important role in the $\mathrm{pH}$ activity profile of family 11 xylanases. This study provided alkalophilic mutants for application in bleaching process, and it was also helpful to understand the alkaline adaptation mechanism of family 11 xylanases.
\end{abstract}

Keywords: Xylanase, Alkalophilicity, Error-prone PCR, Site-directed mutation, Site-saturation mutagenesis, Catalytic efficiency

\section{Background}

Xylan is the second most abundant renewable resource in nature, following cellulose. It is composed of a backbone of $\beta$-1,4-linked D-xylopyranose residues, and its side chain is modified by different groups, such as acetate, D-glucuronate, 4-O-methyl-D-glucuronate, and

\footnotetext{
* Correspondence: bai_wq@tib.cas.cn; jiaxueshi@163.com ${ }^{1}$ Department of Strategic and Integrative Research, Tianjin Institute of Industrial Biotechnology, Chinese Academy of Sciences, 300308 Tianjin, China ${ }^{2}$ College of Life Science, Shanxi Normal University, Linfen 041004, China
}

$\alpha$-L-arabinofuranose [1]. Because of its complex structure, the complete degradation of xylan requires the cooperative action of a variety of enzymes. Among them, endo- $\beta$ 1, 4-xylanase (EC 3.2.1.8) is the crucial enzyme to randomly hydrolyze $\beta$-1,4-xylosidic linkages of xylan to xylooligosaccharides [2]. Based on hydrophobic cluster analysis and amino acid sequence similarities, xylanases are mainly classified into glycoside hydrolase $(\mathrm{GH})$ families 10 and 11 [3]. Due to their ability to degrade xylan, xylanases have potential biotechnological applications in 
many fields [2]. A major application of xylanases is in the paper industry, in which the enzyme can reduce the amount of toxic chlorine-containing chemicals and improve the pulp brightness [4]. For example, pretreatment with Cartazyme HS-10 could reduce the chlorine consumption by $31 \%$ at C-stage and $30 \%$ reduction in total organochlorine content in the extraction stage effluent. The brightness was increased by 4.9 points in $\mathrm{CEH}$ sequence [5].

Family 11 xylanases can easily penetrate cellulose fiber networks without damaging the fibers because of their small molecular mass (about $20 \mathrm{kDa}$ ) and cellulase-free activity. Therefore, they are more suitable for the pulp bleaching process than family 10 enzymes [6]. Because the pulp bleaching process is usually in a high temperature $\left(60-80{ }^{\circ} \mathrm{C}\right)$ and high $\mathrm{pH}(8-10)$ environment [2], the xylanases for this application are required to be thermophilic, thermostable, alkaliphilic, and alkali-stable [7, 8]. Although many xylanases have been cloned and characterized (http://www.cazy.org/GH11_characterized.html), few xylanases were found to be active and stable in the high temperature and alkaline condition. Therefore, engineering the native enzymes to achieve high activity and stability at high temperature and $\mathrm{pH}$ is in great demand.

Although many attempts on the modification of xylanases by rational design or directed evolution have been successful, such as increasing the optimal temperature or the catalytic activity of the enzyme [9-11], research on the improvement of alkalophilicity of the xylanase is limited [12]. Most of the mutations decreased the optimal $\mathrm{pH}$ of the enzyme [13, 14], or only shifted the optimum from acidity to neutrality rather than to the alkaline range $[7,15,16]$. Introducing excess arginine residues on the protein surface could increase the optimal pH of xylanase XynJ from aklaliphilic Bacillus sp. 41M-1 from 8.5 to 9.5 [17], but we could not replicate the result with the equivalent mutational change in the other xylanse in our previous study.

In the previous study, an alkaline xylanase Xyn11A-LC from Bacillus sp. SN5 was characterized [18]. It exhibited the highest catalytic activity at $\mathrm{pH} 7.5$, but little enzyme activity could be detected at $\mathrm{pH}$ 10.0. This property was not suitable for the pulp bleaching process. The three dimensional structure of xylanase Xyn11A-LC has been determined [19]. The molecular basis of alkaline adaptation of family 11 xylanase has been revealed [20]. These studies will contribute to engineer non-alkaline xylanase to function at a higher $\mathrm{pH}$ condition, but it is still hard to further improve the alkalophilicity of an alkaline xylanase by rational protein design. In this study, in order to obtain more alkaline mutants, a random mutation library of xylanase Xyn11A-LC was constructed by error-prone PCR. One mutant with improved alkalophilicity was obtained by a high-throughput screening system. Site-directed mutations and site-saturation mutagenesis were then carried out to validate the key role of the residue at position 135 on the $\mathrm{pH}$ activity profile of Xyn11A-LC. The mechanism of alkaline adaptation of the mutant was discussed by structural analysis.

\section{Results \\ Construction and screening of random mutagenesis libraries}

Over 10,000 colonies were obtained from the random mutagenesis libraries. About 6000 transformants showing clear halos on the medium with Remazol Brilliant Blue xylan (RBB-xylan) were picked into 96-well plates for screening for the mutants with improved alkalophilicity. The selection criterion was an increase of at least $10 \%$ in the $\mathrm{pH} 10 / \mathrm{pH} 7.5$ activity ratio of the mutants compared to that of the wild type. For the second screening, a total of 54 mutants showing higher ratio than that of the wild type were obtained. Then, according to the $\mathrm{pH}$ activity profiles of crude enzymes of the wild type and 54 mutants, 8 mutants with improved alkalophilicity were obtained in the third screening. For the fourth screening, one mutant M52-C10 with improved alkalophilicity was obtained from above mentioned 8 mutants by determining $\mathrm{pH}$ activity profiles of the purified enzymes (Additional file 1: Figure S1). M52C10 exhibited an optimal activity at $\mathrm{pH} 8.0$ and corresponded to a basic shift of $0.5 \mathrm{pH}$ units compared to the wild-type enzyme. Furthermore, the relative activities of mutant M52-C10 increased by 10, 15, $8 \%$ at pH 8.5, 9.0 and 9.5, respectively (Fig. 1).

\section{Mutation site analysis}

DNA sequencing showed that the mutant M52-C10 had two mutations, V116A and E135V. Site-directed mutagenesis revealed that only the E135V mutation showed the improvement of alkalophilicity (Fig. 1). The optimal $\mathrm{pH}$ of the mutant E135V increased to $\mathrm{pH}$ 8.0, which was $0.5 \mathrm{pH}$ units higher than that of the wild-type enzyme. Compared to the relative activities of the wild type enzyme, those of the mutant E135V increased by 17.5 , $18.9,14.3$ and $9.5 \%$ at $\mathrm{pH}$ 8.5, 9.0, 9.5 and 10.0, respectively. Nevertheless, the $\mathrm{pH}$ activity profile of the mutant V116A was similar to that of the wild type enzyme. According to the above results, it could be concluded that Glu 135 might be one of the key residues involved in determining the $\mathrm{pH}$ activity profile of Xyn11A-LC.

In order to get more information about the influence of Glu 135 on the pH activity profile of Xyn11A-LC and to obtain more alkalophilic mutant, site-saturation mutagenesis was carried out by overlap extension PCR. The result showed that the only mutant to have better alkalophilicity than E135V was E135R. Its optimal $\mathrm{pH}$ was 8.5, $0.5 \mathrm{pH}$ units higher than that of E135V. Mutations 


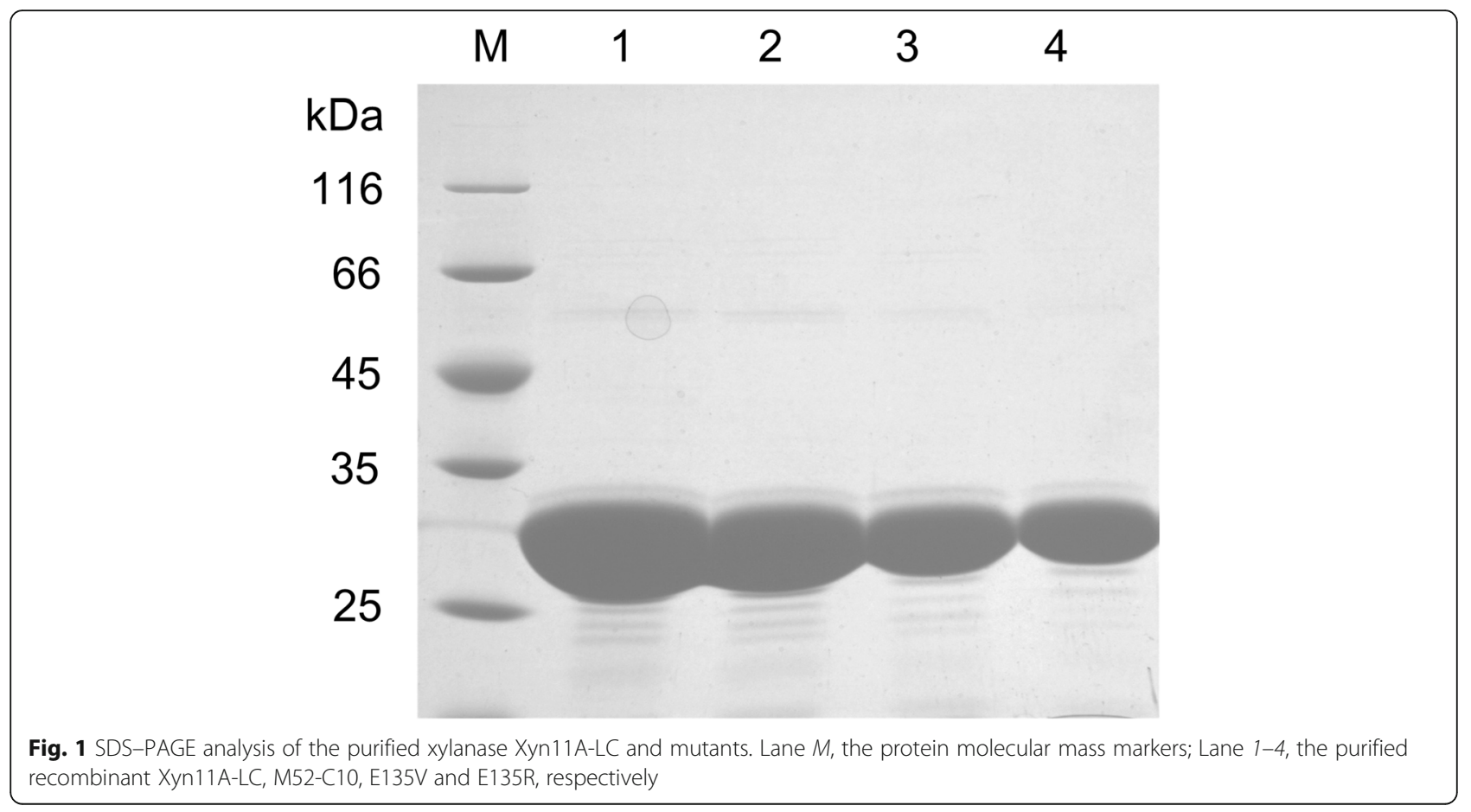

E135H, E135K, E135Q, E135M, E135Y and E135A exhibited maximal activity at $\mathrm{pH} 8.0$, similar to the mutant E135V. The optimal $\mathrm{pH}$ of E135P was 6.0, 1.5 $\mathrm{pH}$ units lower than that of the wild-type. The ten other mutations exhibited maximal activity at $\mathrm{pH} 7.5$, similar to the wild-type (Fig. 2).

\section{Characterization of the mutants and the wild type enzyme}

To further elucidate the effects of Glu 135 site substitutions on enzyme characterization, other characterizations of the wild type and the mutants were determined. The mutants E135V and E135R were both stable over a broad $\mathrm{pH}$ range, retained over $80 \%$ of original activity after incubation at $37{ }^{\circ} \mathrm{C}$ for $1 \mathrm{~h}$ over a $\mathrm{pH}$ range from 4.5 to 10.0 , while the wild-type enzyme was stable only at alkaline $\mathrm{pH}$ from 8.0 to 10.0 (Fig. 2b). The optimal temperatures of the mutants M52-C10, E135V and E135R were all $55{ }^{\circ} \mathrm{C}$, which was similar to that of the wild type. However, the mutants exhibited higher relative activity at the temperature range of $30-70{ }^{\circ} \mathrm{C}$ (Fig. 2c). In addition, the thermostability of the mutants was also determined. After incubation at $60{ }^{\circ} \mathrm{C}$ for 30 min, the mutants M52-C10, E135V and E135R retained $57.4,73.1$ and $77.8 \%$ of their maximal activities, respectively, while the wild type enzyme only retained $33.5 \%$ of its activity under the same conditions (Fig. 2d). This result showed that the displacement of the negative charge on the surface increased the thermostability of xylanase Xyn11A-LC.
The kinetic parameters of the wild type enzyme and the mutants toward beechwood xylan were determined under their optimal conditions. The $K_{\mathrm{m}}, V_{\max }$, and $k_{\text {cat }}$ values of the enzyme were shown in Table 1. Compared with the wild type, the mutants M52-C10, E135V and E135R had lower $K_{\mathrm{m}}$ values, which indicated that the Glu 135 mutation increased the substrate affinity. Additionally, the $V_{\max }$ values and $k_{\text {cat }}$ values of the mutant E135V and E135R are all higher than those of the wild type. Compared with the wild-type enzyme, the mutations E135V and E135R increased the catalytic efficiency $\left(k_{\text {cat }} / K_{\mathrm{m}}\right)$ by 57 and $37 \%$, respectively.

\section{Structural analyses of the mutants}

Some amino acid residues close to the catalytic residues (Glu 93 and Glu 183) are presumed to be responsible for the $\mathrm{pH}$ activity profile of Xyn11A-LC by changing the electrostatic potential of the active site [20]. However, the residue Glu 135 is far away from the two catalytic residues (Glu 93 and Glu 183). The distance between Glu 135 $\mathrm{O} \varepsilon 1 / \mathrm{O} \varepsilon 2$ and Glu $93 \mathrm{O} \varepsilon 1 / \mathrm{O} \varepsilon 2$ is $12.12,12.30,13.22$ and $13.23 \AA$, respectively, whereas the distance between Glu $135 \mathrm{O} \varepsilon 1 / \mathrm{O} \varepsilon 2$ and Glu 183 Oe1/Oع2 is 19.12, 19.60, 19.90 and $20.53 \AA$, respectively. Xyn11A-LC has the $\beta$-jelly roll structure typical of family 11 xylanases (Fig. 3a), which is also likened to the shape of a 'right hand' [21]. The eightresidue loop (Gln 131, Pro 132, Ser 133, Ile 134, Glu 135, Gly 136, Thr 137, and Ala 138) forms a 'thumb' that partly encloses the catalytic cleft. Glu 135 is located at the edge of the 'thumb' (Fig. 3a). The sequence and structure of the 

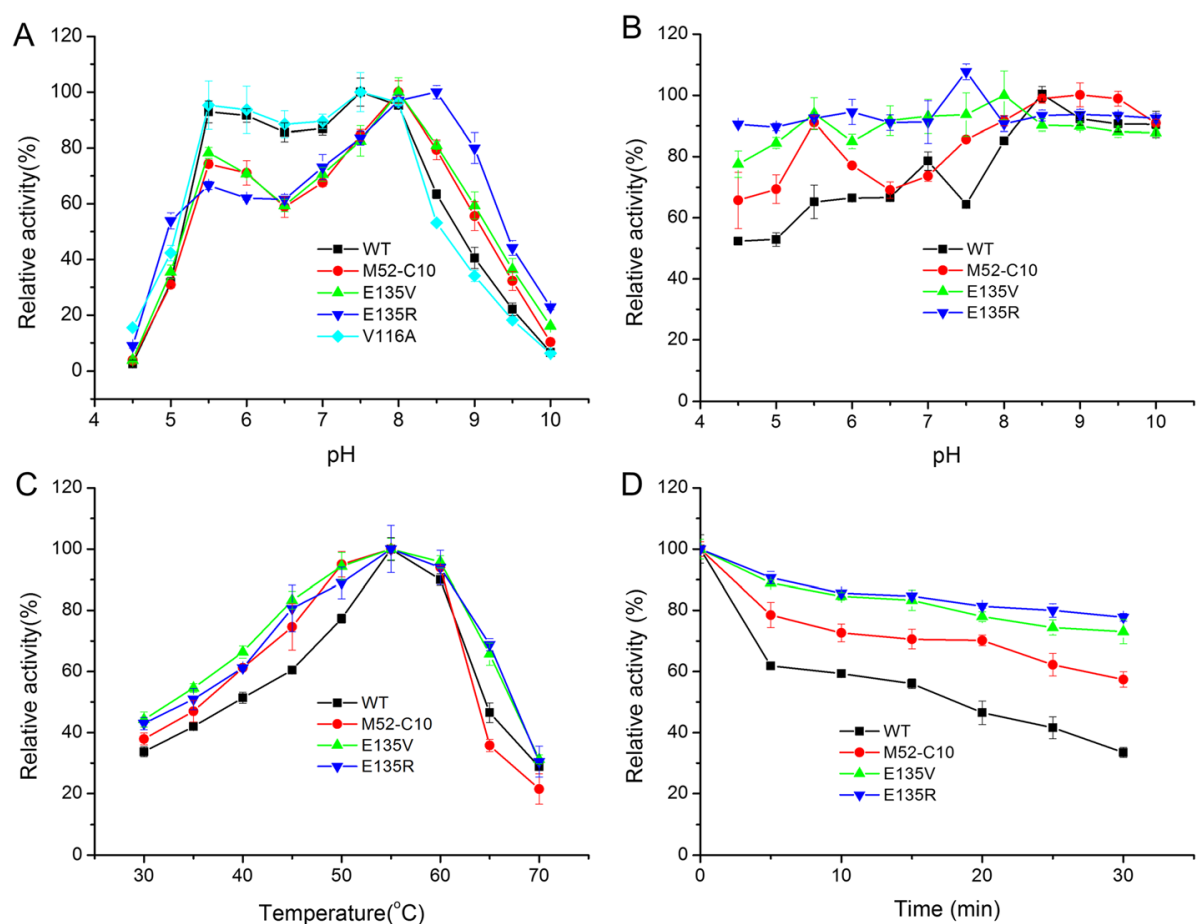

Fig. 2 Effects of $\mathrm{pH}$ and temperature on the activity and stability of the recombinant Xyn11A-LC and mutants. a Effect of pH on the activity of Xyn11A-LC and mutants. The assay was performed in different $\mathrm{pH}$ buffer ranging from $\mathrm{pH} 4.5$ to $\mathrm{pH} 10.0$ at optimal temperature for 10 min. b Effect of pH on the stability of Xyn11 A-LC and mutants. The enzyme was diluted in different buffer $(\mathrm{pH} 4.5-\mathrm{pH} 10.0)$ at $37^{\circ} \mathrm{C}$ for an hour, and the residual activities were measured at the optimal condition for $10 \mathrm{~min}$. The activity of the purified enzyme without pre-incubation was set as $100 \%$. c Effect of temperature on the activity of Xyn11A-LC and mutants. The assay was performed at different temperature ranging from 30 to $70{ }^{\circ} \mathrm{C}$ for 10 min. $\mathbf{d}$ Effect of temperature on the stability of Xyn11A-LC and mutants. The purified enzymes were incubated in $50 \mathrm{mM}$ Tris- $\mathrm{HCl}$ buffer ( $\mathrm{pH}$ 8.0) without substrate for $30 \mathrm{~min}$ at $60^{\circ} \mathrm{C}$, respectively and taken out every $5 \mathrm{~min}$. The residual xylanase activities were measured under the optimal condition for $10 \mathrm{~min}$. The $0 \mathrm{~min}$ value was set as $100 \%$

eight-residue loop of 13 family 11 xylanases, which were optimally active in acidic, neutral, or alkaline $\mathrm{pH}$ range, were compared, as shown in Table 2. The triad of residues that forms the tip of the thumb (Pro 132, Ser 133, and Ile $134)$ and Gly 136 are conserved in family 11 xylanase. The position 135 residue was a lysine residue in those xylanases with higher optimal $\mathrm{pH}$, the corresponding residue is a glutamate or asparte residue in Xyn 11A-LC and some xylanases with lower optimal $\mathrm{pH}$. In addition, the lysine residue in the eight-residue loop in higher alkaline xylanases was involved in the formation of a salt bridge (Table 2). It would be speculated that the elimination of the negative charge, the introduction of the positive charge, or the salt-bridge in the position 135 might be involved in the alkaline adaptation of xylanase.
The mutation E135V with improved alkalophilicity might prove that the elimination of the negative charge at position 135 could contribute to the alkaline adaptation of xylanase. In order to validate the positive charge at position 135, the $\mathrm{pH}$ activity profiles of the mutations E135H, E135K and E135R were compared with E135V. The result showed that the $\mathrm{pH}$ activity profiles of the mutations $\mathrm{E} 135 \mathrm{H}$ and $\mathrm{E} 135 \mathrm{~K}$ were similar to that of the E135V mutation, but E135R had higher alkapholicity than E135V, its optimal pH was increased to 8.5 (Fig. 2a). The structural analysis showed that a putative saltbridge could be established between the introduced Arg 135 and Asp 89 because of a large guanidinium group of arginine, but it didn't exist between Lys/His 135 and Asp 89 (Fig. 3b). The superior performance for Arg 135

Table 1 The kinetic parameters of the wild-type enzyme and the mutants

\begin{tabular}{lcccr}
\hline Parameter & WT & M52-C10 & E135V & E135R \\
\hline$K_{\mathrm{m}}\left(\mathrm{mg} \mathrm{ml}^{-1}\right)$ & $3.3 \pm 0.2$ & $3.0 \pm 0.4$ & $2.5 \pm 0.6$ & $2.6 \pm 0.5$ \\
$V_{\max }\left(\mu \mathrm{mol} \mathrm{min}{ }^{-1} \mathrm{mg}^{-1}\right)$ & $7178 \pm 186$ & $7355 \pm 324$ & $8546 \pm 654$ & $7734 \pm 602$ \\
$k_{\text {cat }}\left(\mathrm{s}^{-1}\right)$ & $3230 \pm 84$ & $3310 \pm 146$ & $3846 \pm 294$ & $3480 \pm 271$ \\
$k_{\text {cat }} / K_{\mathrm{m}}\left(\mathrm{ml} \mathrm{mg}^{-1} \mathrm{~s}^{-1}\right)$ & $978 \pm 25$ & $1103 \pm 48$ & $1538 \pm 118$ & $1339 \pm 104$ \\
\hline
\end{tabular}




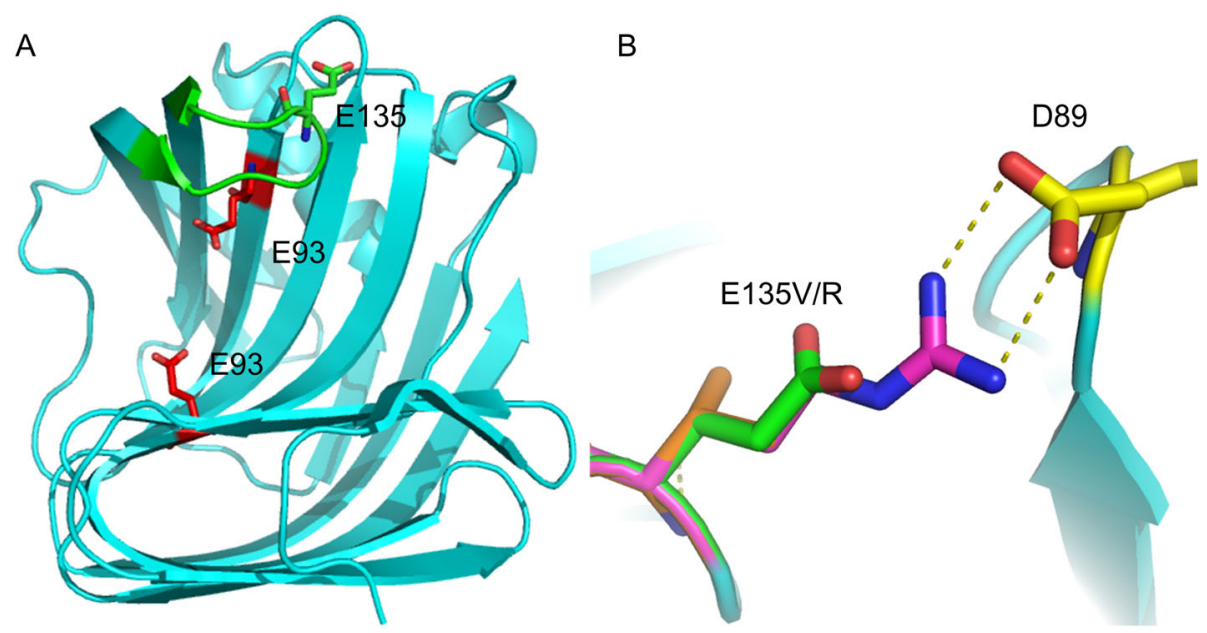

Fig. 3 Locations and structural analysis of three key mutation sites. a Mutation location in the crystal structure of Xyn11A-LC (PDB accession no. $4 \mathrm{XL}$ ). The side chains of the catalytic residues (E93 and E183) and mutation (E135) are shown in red and green, respectively. A 'thumb' formed by the eight-residue loop is shown in green. $\mathbf{b}$ Location and mutation of E135V/R. E135, V135 and R135 are shown in green, orange, and purple, respectively. Salt bridges are represented in yellow by dashed lines

relative to Lys 135 or His 135 suggests that the bidentate hydrogen bonding that is geometrically feasible for Arg 135 has more importance than simply the presence of a positive charge at this site.

\section{Discussion}

Research on xylanase used in the paper industry has attracted increasing attention because it can reduce the cost, lower environmental pollution and improve the pulp quality. It requires the xylanase to be stable and active at high temperature and alkaline $\mathrm{pH}$ [2]. However, most of the xylanases are reported to be mesophilic or acidophilic enzymes. In this study, directed evolution of the enzyme was used by error-prone PCR. Xyn11A-LC was successfully engineered to improve its alkaline adaptation for potential industrial application for the pulp bleaching process.

The mutations E135V, E135K, E135H, E135A, E135Q, $\mathrm{E} 135 \mathrm{M}$, and E135Y all increased the optimal $\mathrm{pH}$ from 7.5 to 8.0. Furthermore, E135R increased the optimal pH from 7.5 to 8.5 (Fig. 2a). However, the optimal pH of E135P was 6.0, $1.5 \mathrm{pH}$ units lower than that of the wildtype. It is speculated that a proline at position 135 is incompatible with the phi/psi for this beta turn, or it is likely to cause disruption through steric incompatibility with neighboring residues. Other studies also proved

Table 2 Sequence and structure comparison of the eight-residue loops of family 11 xylanases

\begin{tabular}{|c|c|c|c|c|c|}
\hline Enzyme abbreviation & Source & PDB code & Eight-residue loop sequence & Salt-bridge in the eight-residue loop & Optimum pH \\
\hline XynJ ( $\triangle X B D)$ & Bacillus sp. 41M-1 & 2DCK & QPSIKGGTA & Lys135- Glu55 & $9[17]$ \\
\hline Xyl C & $\begin{array}{l}\text { alkalophilic Bacillus } \\
\text { (NCL 87-6-10) }\end{array}$ & $2 \mathrm{~F} 6 \mathrm{~B}$ & QPSIㅡGIA & Lys136-Glu56 & $8[35]$ \\
\hline BadX & Bacillus agaradhaerens AC13 & $1 \mathrm{H} 4 \mathrm{G}$ & QPSIㅡGIA & Lys136- Glu56 & $8[36]$ \\
\hline Xyn11X & Bacillus subtilis B230 & $11 \mathrm{GO}$ & QPSIIIGIA & NA & $8[37]$ \\
\hline Xyn11A-LC & Bacillus sp SN5 & $4 \mid X L$ & QPSIEGTA & NA & $7.5[18]$ \\
\hline XynA & Bacillus subtilis 168(1A1) & $1 X X N$ & APSIDGDR & NA & $6-6.5[38]$ \\
\hline Xyl1 & Streptomyces sp. S38 & $1 \mathrm{HIX}$ & APSVEGGTK & NA & $6[39]$ \\
\hline$B c x$ & Bacillus circulans & $1 \mathrm{XNB}$ & APSIDGDR & NA & $5.7[40]$ \\
\hline Xyn2 & Hypocrea jecorina RUT-C30 & $1 X Y O$ & QPSIIGTA & NA & $5.3[21]$ \\
\hline $\mathrm{XYNI}$ & Trichoderma reesei & $1 X Y N$ & EPSI $\underline{\mathbf{Q}} \mathrm{GTA}$ & NA & $3.5[41]$ \\
\hline XYL1 & Scytalidium acidophilum & $3 \mathrm{M} 4 \mathrm{~F}$ & EPSITGTS & NA & $3.2[42]$ \\
\hline XynA & Aspergillus niger CBS 513.88 & $1 U K R$ & EPSI $\underline{T} G T S$ & NA & $3[43]$ \\
\hline XynC & Aspergillus kawachii & 1BK1 & EPSITGTS & NA & $2[44]$ \\
\hline
\end{tabular}

The key residues involved in the $\mathrm{pH}$ adaptation of enzymes are in bold and underlined 
that the substitution of the residue in other xylanases corresponding to Glu 135 in xylanase Xyn11A-LC could also change the $\mathrm{pH}$ activity profile of enzymes. The E141A mutation in XYL1p from Scytalidium acidophilum increased the optimal $\mathrm{pH}$ from 3.2 to 4.0 [22]. The E141Q mutation in XynI from Aureobasidium pullulans changed the optimal pH from 2.5 to 3.5 [23]. The mutation E139K of Xyl1 of Streptomyces sp. S38 significantly raised the $\mathrm{pH}$ optimum from 6.0 to 7.5 [24]. Therefore, the position 135 site may play an important role in determining the $\mathrm{pH}$ activity profile of family 11 xylanase.

The residue Glu 135 located at the edge of the 'thumb' could also influence the catalytic activity of the enzyme. Two mutations (E135V and E135R) of xylanase Xyn11ALC increased the catalytic activities to a different extent. The mutations E118A and E118Q of xylanase from Aspergillus niger for the same key position increased the activity by 50 and $16 \%$, respectively [25]. The same result was shown in XYL1p from S. acidophilum where E141A mutation elevated the specific activity by $50 \%$ [22]. Furthermore, the importance of this residue in the catalytic activity of family 11 xylanases was confirmed by the inverse mutation, the mutation A139E in Xyl1 of Streptomyces sp. S38 decreased its specific activity by $75 \%$ [26].

It was reported that the residues in the eight-residue loop were important in determining the $\mathrm{pH}$ optima of family 11 xylanase $[7,27]$. The residue Glu 135 was located at the edge of the eight-residue loop on the protein surface (Fig. 3a). The substitution of Glu 135 residue with the valine residue might improve the alkalophilicity of the enzyme by eliminating the negative charge on the surface. The mutation E135R might further improve the alkalophilicity by introduction of arginines residues and a salt-bridge on the surface. The $\mathrm{pH}$-dependent activity of the enzyme depends on the ionization of catalytic acid residues sensitive to the surface charge of the protein. Changing the surface charge of the enzyme could significantly shift the $\mathrm{pH}$-activity profiles of the enzymes by changing the $\mathrm{p} K_{\mathrm{a}}$ value of the active site, despite the two groups are far away from each other [28]. In our previous work, an increase in the number of the positive charge residues (Arg and Lys) and a decrease in the Glu residue on the protein surface were involved in the mechanism of alkaline adaptation of the family 11 xylanases, because the basic residues have high $\mathrm{pK}$ a values and can retain net positive charge even at high $\mathrm{pH}$ [20]. Several studies showed that increasing the number of arginines on the protein surface could improve the alkalophilicity of enzymes [17, 29]. In addition, there was a positive correlation between the number of salt bridges and alkaline adaptation of family 11 xylanases [20]. Other studies also indicated that the characteristic salt bridges in the catalytic cleft could contribute to the alkalophilicity of an alkaline xylanase XynJ from aklaliphilic Bacillus sp. 41M-1 [17, 30]. The salt bridge in the eight-residue loop might be beneficial to the stability of the enzyme in the alkaline condition and thus improve the alkalophilicity of the enzyme.

Research has indicated that the eight-residue loop possesses an opening and closing capability that modifies both the topology and the binding capacity of the active site, and the loop's precise position determines the width of the catalytic cleft [27, 31]. Although, the residue Glu135 is far from the active site, it is located at the edge of the substrate binding cleft. The displacement of Glu 135 residue might eliminate the electrostatic repulsions between the cleft and the xylan which has a certain degree of negative charge because of glucuronic acid substituents [23]. This could increase the binding ability of the substrate and the cleft [23]. An intimate interaction with the substrate might protect the catalytic residues within the active site from the solvent and therefore allow the enzyme to function at a higher $\mathrm{pH}$ condition. It is also the possible cause of the decrease of the $K_{\mathrm{m}}$ values in the two mutations E135V and E135R. The position of the loop may be changed when a larger substrate binds in a slightly different conformation, which changes the distances between the catalytic residues and the substrate and thus affects the catalytic activity of the enzyme [32].

\section{Conclusion}

Using directed evolution followed by site-directed mutagenesis, the residue at position 135 in Xyn11A-LC was speculated to be one of the key amino acids responsible for the $\mathrm{pH}$ activity profile of the enzyme. Furthermore, sequence alignment and structural analysis of family 11 xylanases with different optimum $\mathrm{pH}$ showed that the residue at position 135 located at the edge of the 'thumb' could affect the alkalophilicty by the elimination of the negative charge and the information of the salt-bridge. It will be useful to understand the alkaline adaptation of family 11 xylanases and engineer the enzyme to function at a higher $\mathrm{pH}$ condition. The mutant E135R is a promising and suitable candidate for paper pulp bio-bleaching.

\section{Methods}

\section{Strains, plasmids, enzymes and reagents}

The recombinant plasmid pET 28a-Xyn11A-LC was constructed by our research group [18]. E.coli BL21Gold (DE3) strain was used as a host for the random mutagenesis library. E.coli BL21 (DE3) was used for protein production. GeneMorph II Random Mutagenesis Kit was purchased from Agilent technologies (USA). Beechwood xylan and RBB-xylan were purchased from Sigma (USA). 


\section{Construction of random mutagenesis library}

The random mutagenesis library was constructed by error-prone PCR using GeneMorph II Random Mutagenesis Kit according to the manual. The recombinant plasmid pET 28a-Xyn11A-LC was used as a template. In order to achieve medium mutation rate, initial target amount of template DNA is about 100 ng. The mutant gene was amplified by PCR using the primers ep-F and ep-R listed in Additional file 1: Table S1. The PCR cycling conditions were as follows: $2 \mathrm{~min}$ at $95{ }^{\circ} \mathrm{C}$, then 30 cycles of $30 \mathrm{~s}$ at $95{ }^{\circ} \mathrm{C}, 30 \mathrm{~s}$ at $57{ }^{\circ} \mathrm{C}$, and $30 \mathrm{~s}$ at $72{ }^{\circ} \mathrm{C}$, followed by $10 \mathrm{~min}$ at $72{ }^{\circ} \mathrm{C}$. The PCR products were purified using the gel extraction kit (Omega), digested with BamHI and XhoI, and then ligated into the pET28a between BamHI and XhoI sites. The resulting plasmids were transformed into E.coli BL21-Gold (DE3) competent cells by electro transformation and plated on LKX medium (Luria-Bertani agar plate, $50 \mu \mathrm{g} / \mathrm{ml}$ kanamycin, $0.2 \%$ RBB-xylan, pH 9.0) [18].

\section{Screening for alkalophilic xylanase mutants}

The colonies showing clear halos on above mentioned LKX medium were picked up and inoculated into $160 \mu \mathrm{l}$ LBK medium (LB medium supplemented with $50 \mu \mathrm{g} / \mathrm{ml}$ kanamycin) in 96-well microplates for growth overnight at $37{ }^{\circ} \mathrm{C}$ with shaking at $900 \mathrm{rpm}$. Every mutant in the microplates was then replicated into fresh LBK medium containing $0.1 \mathrm{mM}$ isopropyl $\beta$-D-1-thiogalactopyranoside (IPTG). After cultivation at $37^{\circ} \mathrm{C}$ for $10 \mathrm{~h}$, the cells were harvested by centrifugation at $4000 \mathrm{rpm}$ at $4{ }^{\circ} \mathrm{C}$ for $10 \mathrm{~min}$, re-suspended with lysis buffer $(50 \mathrm{mM}$ Tris$\mathrm{HCl}$ buffer containing $10 \mathrm{mg} / \mathrm{ml}$ lysozyme, $\mathrm{pH} 8.0$ ), and incubated at $37^{\circ} \mathrm{C}$ for $60 \mathrm{~min}$. The cell lysates were diluted 100-fold and used as the crude enzyme extract for downstream enzymatic reactions.

To screen the mutants with improved alkaline adaptation, xylanase activities were measured at $\mathrm{pH} 7.5$ and $\mathrm{pH} 10.0$, respectively. $10 \mu \mathrm{l}$ of the crude enzyme extract was incubated with $100 \mu \mathrm{l} 1 \%$ beechwood xylan $(w / v)$ dissolved in $50 \mathrm{mM}$ Tris- $\mathrm{HCl}$ buffer $(\mathrm{pH} 7.5)$ and $50 \mathrm{mM}$ Glycine- $\mathrm{NaOH}(\mathrm{pH}$ 10.0), respectively. After incubation at $55{ }^{\circ} \mathrm{C}$ for $10 \mathrm{~min}$, the released reducing sugars were assayed by the 3,5-dinitrosalicylic acid (DNS) method using xylose as the standard [33]. The variants with higher $\mathrm{pH}$ 10.0/ $\mathrm{pH} 7.5$ activity ratio than the wild type were considered as mutants with improved alkalophilicity. For the third screening, the mutants with significantly improved alkalophilicity were selected by detecting crude xylanase activity at $\mathrm{pH}$ from 7.0 to 10.0. For the fourth screening, the positive mutants were selected by determining the purified enzyme activity at $\mathrm{pH}$ from 4.5 to 10.0 .

\section{Site-directed mutagenesis and site-saturation} mutagenesis

Site-directed mutagenesis and site-saturation mutagenesis were performed using the overlap-extension PCR method with Phusion Hot Start II High-Fidelity DNA Polymerase as described [19]. The plasmid pET28aXyn11A-LC was used as the template. The primers containing mutated codons were listed in Additional file 1: Table S1. The PCR cycling conditions were listed as follows: $30 \mathrm{~s}$ at $98{ }^{\circ} \mathrm{C}$, then 20 cycles of $30 \mathrm{~s}$ at $98{ }^{\circ} \mathrm{C}$, $30 \mathrm{~s}$ at $55^{\circ} \mathrm{C}$, and $3 \mathrm{~min}$ at $72{ }^{\circ} \mathrm{C}$, followed by $10 \mathrm{~min}$ at $72{ }^{\circ} \mathrm{C}$. The amplification products were digested by $D p n \mathrm{I}$ overnight at $37{ }^{\circ} \mathrm{C}$ and then transformed into E. coli BL21 (DE3) competent cells by electro transformation. The mutant xylanase gene from the transformants was verified by DNA sequencing performed by Genewiz BioSciences Company (Beijing, China).

\section{Expression and purification of enzymes}

A single colony of strain BL21(DE3) harboring plasmid carrying gene of Xyn11A-LC or its mutant was grown in LBK medium at $37^{\circ} \mathrm{C}$ until the OD600 reached 0.6-0.8. After a supplement with $1 \mathrm{mM}$ IPTG, the culture was induced at $37{ }^{\circ} \mathrm{C}$ for $6 \mathrm{~h}$. Cells were harvested by centrifugation at $8000 \mathrm{rpm}$ for $10 \mathrm{~min}$ and disrupted by sonication in the lysis buffer $(20 \mathrm{mM}$ Tris- $\mathrm{HCl}, 500 \mathrm{mM}$ $\mathrm{NaCl}, 10 \mathrm{mM}$ imidazole, $\mathrm{pH}$ 8.0). Cell debris was removed by centrifugation at $16,000 \mathrm{rpm}$ at $4{ }^{\circ} \mathrm{C}$ for $20 \mathrm{~min}$. The supernatants were loaded on a nickel-nitrilotriacetic acid (Ni-NTA) column (Qiagen, Valencia, CA, USA) which was pre-equilibrated with the lysis buffer. Then the column was washed with washing buffer $(20 \mathrm{mM}$ Tris- $\mathrm{HCl}, 500 \mathrm{mM} \mathrm{NaCl}, 60 \mathrm{mM}$ imidazole, $\mathrm{pH} 8.0$ ) and the bound protein was eluted with the elution buffer $(50 \mathrm{mM}$ Tris- $\mathrm{HCl}, 500 \mathrm{mM} \mathrm{NaCl}, 1 \mathrm{M}$ imidazole, $\mathrm{pH}$ 8.0). Imidazole was removed by using a desalting column (GE Healthcare Bio-Sciences AB, Uppsala, Sweden) with $20 \mathrm{mM}$ Tris-HCl buffer ( $\mathrm{pH}$ 8.0). The purity of the proteins was analyzed by the sodium dodecyl sulfate polyacrylamide gel electrophoresis (SDSPAGE). Protein concentrations were determined by a protein assay kit (Bio-Rad).

\section{Enzyme activity}

The enzyme activities of the wild type Xyn11A-LC and its mutants were assayed by measuring the amount of reducing sugars from beechwood xylan by DNS method [33]. The reaction mixture containing $20 \mu \mathrm{l}$ of $1 \mu \mathrm{g} / \mathrm{ml}$ xylanase solution and $480 \mu \mathrm{l}$ of $1 \%$ beechwood xylan $(w / v)$ in different buffer was incubated in $55{ }^{\circ} \mathrm{C}$ for $10 \mathrm{~min}$. After supplemented with $500 \mu \mathrm{l}$ of DNS reagent, the mixture was boiled for $5 \mathrm{~min}$ and cooled to room temperature. Then the absorbance at $540 \mathrm{~nm}$ was determined with Spectra Max 190 microplate reader 
(Molecular Devices, Sunnyvale, CA, USA). One unit (U) of xylanase activity was defined as the amount of enzyme that released reducing sugar from xylan equivalent to $1 \mu \mathrm{mol}$ xylose per minute under the assay condition. The assays were all performed in triplicate.

\section{$\mathrm{pH}$ activity profile and $\mathrm{pH}$ stability of the wild type and mutants}

The effects of $\mathrm{pH}$ on the enzyme activity of the wild type Xyn11A-LC and its mutants was measured at $55{ }^{\circ} \mathrm{C}$ at $\mathrm{pH}$ from 4.5 to 10.0. The maximum value was set as $100 \%$. For $\mathrm{pH}$ stability, the purified xylanases were diluted to $2 \mu \mathrm{g} / \mathrm{ml}$ in different buffers with $\mathrm{pH}$ ranging from 4.5 to 10.0 and pre-incubated without substrate at $37{ }^{\circ} \mathrm{C}$ for $1 \mathrm{~h}$. The residual activities were measured under optimal conditions. The enzyme activity of the purified xylanases without pre-incubation was set as $100 \%$. The buffers used were citrate- $\mathrm{Na}_{2} \mathrm{HPO}_{4}$ for $\mathrm{pH}$ 4.5-8.0, $50 \mathrm{mM}$ boric acid/borate for $\mathrm{pH}$ 8.0-9.0, and $50 \mathrm{mM}$ borate/ $\mathrm{NaOH}$ for $\mathrm{pH}$ 9.5-10.0, respectively.

\section{Optimal temperature and thermostability}

The effect of temperature on the xylanase activity was measured at optimal $\mathrm{pH}$ and a temperature range (30$70{ }^{\circ} \mathrm{C}$ ). The maximum value was set as $100 \%$. For thermal stability, the purified xylanases were diluted to $2 \mu \mathrm{g} /$ $\mathrm{ml}$ in $50 \mathrm{mM}$ Tris- $\mathrm{HCl}$ buffer ( $\mathrm{pH} 8.0$ ), incubated at $60{ }^{\circ} \mathrm{C}$ and then taken out at an interval of $5 \mathrm{~min}$. After incubation, the enzyme solution was immediately put in an ice bath for $10 \mathrm{~min}$. The residual enzyme activities were assayed under optimal condition. The enzyme activity of purified protein without pre-incubation was set as $100 \%$.

\section{The kinetic parameters assay}

To assay the kinetic parameters $K_{\mathrm{m}}$ and $V_{\max }$, reaction mixtures containing $1 \mu \mathrm{g} / \mathrm{ml}$ purified xylanases and different concentration of beechwood xylan (1-10 mg/ $\mathrm{ml}$ ) were incubated at optimum $\mathrm{pH}$ and temperature. The Michaelis-Menten parameters were calculated by nonlinear regression using Graphpad Prism 6.0 software (San Diego, CA, USA). The turn over number $\left(k_{\text {cat }}\right)$ was calculated based on the $V_{\max }$ value and the molecular weight of the targeted enzyme.

\section{Structural analysis}

In our previous work, the structure of the wild type Xyn11A-LC was determined, and the atomic coordinates and structure factors have been submitted to the Protein Data Bank (PDB) under accession code 4IXL [19]. The coordinates of other twelve family 11 mesophilic xylanases with known $\mathrm{pH}$ activity profile were extracted from PDB. Multiple sequence alignment of the amino acid sequences was performed using the ClustalW program. The three dimensional structures of the mutants were modeled using Discovery Studio software. The surface residues of Xyn11A-LC with $30 \%$ accessible surface areas were identified in Swiss-PDB Viewer using the default parameters [34]. Salt bridges were calculated online by submitting the coordinate files to website (http://bioinformatica.isa.cnr.it/ESBRI/); salt bridges were assigned when the distance between the two atoms of opposite charge was less than $4 \AA$. Structure visualization was performed using PyMOL software.

\section{Additional file}

Additional file 1: Figure S1. Schematic diagram of a high-throughput screening of the positive mutant. Table S1. Primers used for random mutagenesis, site-directed mutagenesis and site saturation mutagenesis. (DOC $325 \mathrm{~kb}$ )

\section{Abbreviations}

DNS: 3,5-dinitrosalicylic acid; IPTG: Isopropyl $\beta$-D-1-thiogalactoside; Ni-NTA: Nickel-nitrilotriacetic acid; PDB: Protein Data Bank; RBB-xylan: Remazol Brilliant Blue xylan; SDS-PAGE: Sodium dodecyl sulfate polyacrylamide gel electrophoresis

\section{Acknowledgement}

We thank Maria McClintock and Kevin J. Fox in the University of Minnesota for editing the language.

\section{Funding}

This study was supported by the Natural Science Foundation of China (31400679), the Key Deployment Program of Chinese Academy of Sciences (KSZD-EW-Z-015), the National High Technology Research and Development Program of China (863 Program, 2012AA022203).

\section{Availability of data and materials}

The Nucleic acids sequence supporting the conclusions of this article is available in the GenBank repository (accession number KC163132). The atomic coordinates and structure factors of proteins are available in the Protein Data Bank (PDB code: 4IXL). Other data are included within the article and its Additional file 1.

\section{Authors' contributions}

WQB: corresponding author, conceived this study, designed and supervised the experiments, performed the experiments, analyzed the data and structures, wrote the manuscript; YFC: performed construction and screening of mutant library, site-directed mutagenesis, and characterization of enzyme; $J \mathrm{~L}$ : performed site-saturation mutagenesis and characterization of enzyme; QHW: conceived this study, supervised the experiments, revised the manuscript; ZHJ: corresponding author, conceived the study. All authors have read and approved the manuscript.

\section{Competing interests}

The authors declare that they have no competing interests.

Consent for publication

Not applicable.

Ethics approval and consent to participate Not applicable.

Received: 17 June 2016 Accepted: 21 October 2016 Published online: 08 November 2016

\section{References}

1. Berrin JG, Juge N. Factors affecting xylanase functionality in the degradation of arabinoxylans. Biotechnol Lett. 2008;30(7):1139-50. 
2. Collins T, Gerday C, Feller G. Xylanases, xylanase families and extremophilic xylanases. FEMS Microbiol Rev. 2005;29(1):3-23.

3. Henrissat B. A classification of glycosyl hydrolases based on amino acid sequence similarities. Biochem J. 1991;280(Pt 2):309-16.

4. Beg QK, Kapoor M, Mahajan L, Hoondal GS. Microbial xylanases and their industrial applications: a review. Appl Microbiol Biot. 2001;56(3-4):326-38.

5. Bajpai P, Bhardwaj NK, Bajpai PK, Jauhari MB. The impact of xylanases on bleaching of eucalyptus kraft pulp. J Biotechnol. 1994;38(1):1-6.

6. Bajpai P. Application of enzymes in the pulp and paper industry. Biotechnol Progr. 1999;15(2):147-57.

7. Li F, Xie J, Zhang X, Zhao L. Improvement of the optimum pH of Aspergillus niger xylanase towards an alkaline $\mathrm{pH}$ by site-directed mutagenesis. J Microbiol Biotech. 2015;25(1):11-7.

8. Shoham Y, Schwartz Z, Khasin A, Gat O, Zosim Z, Rosenberg E. Delignification of wood pulp by a thermostable xylanase from Bacillus stearothermophilus strain T-6. In: Microorganisms to combat pollution. Springer; 1992. p. 83-94

9. Dumon C, Varvak A, Wall MA, Flint JE, Lewis RJ, Lakey JH, Morland C, Luginbühl $P$, Healey $S$, Todaro T. Engineering hyperthermostability into a $\mathrm{GH} 11$ xylanase is mediated by subtle changes to protein structure. J Biol Chem. 2008:283(33):22557-64.

10. Zhang ZG, Yi ZL, Pei XQ, Wu ZL. Improving the thermostability of Geobacillus stearothermophilus xylanase XT6 by directed evolution and site-directed mutagenesis. Bioresource Technol. 2010;101(23):9272-8.

11. Joo JC, Pohkrel S, Pack SP, Yoo YJ. Thermostabilization of Bacillus circulans xylanase via computational design of a flexible surface cavity. J Biotechnol. 2010;146(1):31-9

12. Zheng H, Liu Y, Sun M, Han Y, Wang J, Sun J, Lu F. Improvement of alkali stability and thermostability of Paenibacillus campinasensis Family-11 xylanase by directed evolution and site-directed mutagenesis. J Ind Microbiol Biot. 2014;41(1):153-62.

13. Gibbs MD, Reeves RA, Choudhary PR, Bergquist PL. Alteration of the pH optimum of a family 11 xylanase, XynB6 of Dictyoglomus thermophilum. N Biotechnol. 2010;27(6):803-9.

14. Liu X, Qu Y, You F, Liu Y. Studies on the key amino acid residues responsible for the alkali-tolerance of the xylanase by site-directed or random mutagenesis. J Mol Catal B Enzym. 2002;18(4):307-13.

15. Turunen $\mathrm{O}$, Vuorio M. Fenel $F$, Leisola M. Engineering of multiple arginines into the Ser/Thr surface of Trichoderma reesei endo-1,4-beta-xylanase II increases the thermotolerance and shifts the $\mathrm{pH}$ optimum towards alkaline pH. Protein Eng. 2002;15(2):141-5.

16. Chen Y-L, Tang T-Y, Cheng K-J. Directed evolution to produce an alkalophilic variant from a Neocallimastix patriciarum xylanase. Can J Microbiol. 2001;47(12):1088-94.

17. Umemoto H, Ihsanawati, Inami M, Yatsunami R, Fukui T, Kumasaka T, Tanaka N, Nakamura S. Improvement of alkaliphily of Bacillus alkaline xylanase by introducing amino acid substitutions both on catalytic cleft and protein surface. Biosci Biotech Bioch. 2009;73(4):965-7.

18. Bai W, Xue Y, Zhou C, Ma Y. Cloning, expression, and characterization of a novel alkali-tolerant xylanase from alkaliphilic Bacillus sp. SN5. Biotechnol Appl Biochem. 2015;62(2):208-17.

19. Bai W, Zhou C, Xue Y, Huang CH, Guo RT, Ma Y. Three-dimensional structure of an alkaline xylanase Xyn11A-LC from alkalophilic Bacillus sp. SN5 and improvement of its thermal performance by introducing arginines substitutions. Biotechnol Lett. 2014:36(7):1495-501.

20. Bai W, Zhou C, Zhao Y, Wang Q, Ma Y. Structural insight into and mutational analysis of family 11 xylanases: implications for mechanisms of higher ph catalytic adaptation. PLoS One. 2015;10(7):e0132834.

21. Torronen A, Harkki A, Rouvinen J. Three-dimensional structure of endo-1,4-beta-xylanase II from Trichoderma reesei: two conformational states in the active site. EMBO J. 1994;13(11):2493-501.

22. Al Balaa B, Brijs K, Gebruers K, Vandenhaute J, Wouters J, Housen I. Xylanase XYL1p from Scytalidium acidophilum: site-directed mutagenesis and acidophilic adaptation. Bioresour Technol. 2009;100(24):6465-71.

23. Tanaka H, Okuno T, Moriyama S, Muguruma M, Ohta K. Acidophilic xylanase from Aureobasidium pullulans: efficient expression and secretion in Pichia pastoris and mutational analysis. J Biosci Bioeng. 2004;98(5):338-43.

24. De Lemos Esteves F, Gouders T, Lamotte-Brasseur J, Rigali S, Frere JM. Improving the alkalophilic performances of the Xyl1 xylanase from Streptomyces sp. S38: structural comparison and mutational analysis. Protein Sci. 2005;14(2):292-302.
25. Tahir TA, Berrin JG, Flatman R, Roussel A, Roepstorff P, Williamson G, Juge N. Specific characterization of substrate and inhibitor binding sites of a glycosyl hydrolase family 11 xylanase from Aspergillus niger. J Biol Chem. 2002:277(46):44035-43.

26. de Lemos Esteves F, Ruelle V, Lamotte-Brasseur J, Quinting B, Frere JM. Acidophilic adaptation of family 11 endo-beta-1,4-xylanases: modeling and mutational analysis. Protein Sci. 2004;13(5):1209-18.

27. Kim SH, Pokhrel S, Yoo YJ. Mutation of non-conserved amino acids surrounding catalytic site to shift pH optimum of Bacillus circulans xylanase. J Mol Catal B Enzym. 2008;55(3):130-6.

28. Russell AJ, Fersht AR. Rational modification of enzyme catalysis by engineering surface charge. Nature. 1986;328(6130):496-500.

29. Shirai T, Suzuki A, Yamane T, Ashida T, Kobayashi T, Hitomi J, Ito S. Highresolution crystal structure of M-protease: phylogeny aided analysis of the high-alkaline adaptation mechanism. Protein Eng. 1997;10(6):627-34.

30. Umemoto H, Ihsanawati, Inami M, Yatsunami R, Fukui T, Kumasaka T, Tanaka $\mathrm{N}$, Nakamura S. Contribution of salt bridges to alkaliphily of Bacillus alkaline xylanase. Nucleic Acids Symp Ser (Oxf). 2007;51:2.

31. Muilu J, Torronen A, Perakyla M, Rouvinen J. Functional conformational changes of endo-1,4-xylanase II from Trichoderma reesei: a molecular dynamics study. Proteins. 1998;31(4):434-44.

32. Wakarchuk WW, Campbell RL, Sung WL, Davoodi J, Yaguchi M. Mutational and crystallographic analyses of the active site residues of the Bacillus circulans xylanase. Protein Sci. 1994;3(3):467.

33. Miller GL. Use of Dinitrosalicylic acid reagent for determination of reducing sugar. Anal Chem. 1959:31(3):426-8.

34. Guex N, Peitsch MC. SWISS-MODEL and the Swiss-PdbViewer: an environment for comparative protein modeling. Electrophoresis. 1997;18(15):2714-23.

35. Balakrishnan H, Kamal Kumar B, Dutta-Choudhury M, Rele MV. Characterization of alkaline thermoactive cellulase-free xylanases from alkalophilic Bacillus (NCL 87-6-10). J Biochem Mol Biol Biophys. 2002;6(5):325-34.

36. Poon DK, Webster P, Withers SG, McIntosh LP. Characterizing the $\mathrm{pH}-$ dependent stability and catalytic mechanism of the family 11 xylanase from the alkalophilic Bacillus agaradhaerens. Carbohyd Res. 2003;338(5):415-21.

37. Oakley AJ, Heinrich T, Thompson CA, Wilce MC. Characterization of a family 11 xylanase from Bacillus subtillis B230 used for paper bleaching. Acta Crystallogr D Biol Crystallogr. 2003;59(Pt 4):627-36.

38. Ruller R, Rosa JC, Faca VM, Greene LJ, Ward RJ. Efficient constitutive expression of Bacillus subtilis xylanase A in Escherichia coli DH5alpha under the control of the Bacillus BsXA promoter. Biotechnol Appl Biochem. 2006;43(Pt 1):9-15.

39. Georis J, Giannotta F, De Buyl E, Granier B, Frere J. Purification and properties of three endo-beta-1,4-xylanases produced by Streptomyces sp. strain S38 which differ in their ability to enhance the bleaching of kraft pulps*(2). Enzyme Microb Technol. 2000;26(2-4):178-86.

40. McIntosh LP, Hand G, Johnson PE, Joshi MD, Korner M, Plesniak LA, Ziser L, Wakarchuk WW, Withers SG. The pKa of the general acid/base carboxyl group of a glycosidase cycles during catalysis: a 13C-NMR study of Bacillus circulans xylanase. Biochemistry-US. 1996;35(31):9958-66.

41. Torronen A, Rouvinen J. Structural comparison of two major endo-1,4xylanases from Trichoderma reesei. Biochemistry-US. 1995;34(3):847-56.

42. Al Balaa B, Wouters J, Dogne S, Rossini C, Schaus JM, Depiereux E, Vandenhaute J, Housen I. Identification, cloning, and expression of the Scytalidium acidophilum XYL1 gene encoding for an acidophilic xylanase. Biosci Biotechnol Biochem. 2006;70(1):269-72.

43. Krengel U, Dijkstra BW. Three-dimensional structure of endo-1,4-betaxylanase I from Aspergillus niger: Molecular basis for its low pH optimum. J Mol Biol. 1996;263(1):70-8.

44. Ito K, Ogasawara H, Sugimoto T, Ishikawa T. Purification and properties of acid stable xylanases from Aspergillus kawachii. Biosci Biotech Bioch. 1992; 56(4):547-50. 